Vol. 35, No. 2-Spring Issue

\title{
A COMPARISON OF THE EFFECTIVENESS OF THE "TOOTHKEEPER" AND A TRADITIONAL DENTAL HEALTH EDUCATION PROGRAM
}

\author{
By Richard C. Graves, DDS, DrPH,* \\ Donald R. McNeal, DMD, MPH, ${ }^{* *}$ Don P. Haefner, PhD, ${ }^{* * *}$ \\ and Beverly G. Ware, DrPH****
}

The need for evaluation of dental programs has long been recognized and was reinforced recently by a plea for critical, clinical evaluation of programs of preventive dentistry and health education made by the Research Committee of the American Association of Public Health Dentists in San Francisco in 1972.13 The weight of logic supports conducting dental health programs in schools. As early at least as 1942 the school teacher, trained in educational skills, has been considered the most appropriate person to provide dental health education to children. ${ }^{10}$ Because virtually all children attend school, in contrast to the proportion of school age children who visit a dental office with any regularity, the classroom is considered by far the more adequate setting in which to present a dental health education program. ${ }^{3}$ It is now rather well established that programs or procedures which are successful in controlling dental plaque will be effective in reducing gingival inflammation.1,7,8,14 Thus, the combination of capable teachers, the school setting, and an effective dental health program should reduce dental disease, at least gingival inflammation. A vast array of school dental health programs has been promoted over the years, but all-too-often with little or no evaluation of their effectiveness. ${ }^{4,11}$

\section{Study Design}

In 1972, personnel of the Williams Community Education Center (Williams School) in Flint, Michigan requested that faculty members of the Program in Dental Public Health at The University of Michigan serve as consultants for a dental program with an emphasis on disease prevention. The Williams Community Education Center was designed as a total human resource center for the Williams community to demonstrate the utility of the community education concept. The center is composed of the school, a 72 acre park and recreation component, and a community services building, constructed through a grant from the United States Housing and Urban Development program. The community services building contains a small dental clinic with modest funds provided to employ a dental hygienist and to furnish supplies. Operational funding of the services is provided by the Mott Programs Division of the Flint Board of Education and cooperating community agencies.

The consultants and the school personnel in Flint agreed that any program provided should have an educational and preventive emphasis. At that time the Toothkeeper ${ }^{9}$ program (described in more detail in the Smith, et al. publication in this issue) was being promoted actively to the dental profession and to school personnel. School officials in Flint received a Toothkeeper promotional folder ${ }^{2}$ which stated "Toothkeeper is the only curriculum program in the nation that can effectively teach new skills and change behavioral patterns to end the pain, cost and anguish of dental disease." A decision was made

*Assistant Professor of Dental Public Health, Department of Community Health Programs, School of Public Health, The University of Michigan, Ann Arbor 48104

**Associate Professor, Community and Preventive Dentistry, College of Dentistry, The University of Tennessee, Memphis 38117

*** Professor of Health Behavior, Department of Health Behavior and Health Education, and Assistant Dean, School of Public Health, The University of Michigan 48104

****Assistant Professor of Health Education, Department of Health Behavior and Health Education, School of Public Health, The University of Michigan, Ann Arbor 48104 
by the consultants and school personnel to implement the program at Williams School in the 1972-73 school year. Evaluation was determined to be an essential component of any program and that the degree of benefit of the program should be assessed. There was reluctance to withhold a dental program from any of the children and since it was thought likely the program should have an impact greater than no program at all, the decision was made to compare the change produced by Toothkeeper with that resulting from the use of a more traditional program. Consultants from the dental profession as well as school personnel were aware of the dental health education kits provided by the Committee on Dental Health of the Michigan Dental Association. Therefore, it was decided to compare these two programs and to avoid the use of a classical control group receiving no dental program at all.

Elementary school children aged five to 12 years, of Williams School in Flint, Michigan participated in the dental health education program during the 1972-73 school year. For practical reasons randomization of children into experimental groups was done by classrooms so that children in half of the selected classrooms received a relatively traditional dental health education program whereas the other half of the classes of students participated in a relatively new program, Toothkeeper. Stratification of classes by grades was accomplished before randomization so that approximately equal numbers of children in all grades would be in each group. The group termed "Traditional" was exposed to a health education program containing primarily cognitive elements. The kits of dental health education teaching materials utilized included several booklets on dental facts, a teacher's guide, and a list of films recommended by the Michigan Dental Association. The emphasis of this program was largely on the presentation of facts intended to improve knowledge about functional and anatomical considerations of teeth and the importance of oral health. Demonstration models were used in teaching the children including how to brush and floss teeth. This program was primarily an information-oriented, "show-and-tell" approach to dental health education.

The Toothkeeper program emphasized instruction and regular use of toothbrushes, dental floss, and disclosing tablets within the classroom to control dental plaque. The students in this group were engaged in a relatively intensive program of participation for 16 weeks which included supervised brushing and flossing in class. This program was primarily an action-oriented, "show-and-do" approach to dental health education.

\section{Teacher Workshop}

Prior to the initiation of the classroom phase of the project, a half-day, in-service training session was held for all teachers. The teachers were divided into two groups according to the randomly made assignments, and met in separate locations in the school. A Toothkeeper consultant from the Health Education Division of the Den-Tal-Ez Manufacturing Company coordinated the workshop for the Toothkeeper group according to the recommended guidelines of Toothkeeper. The Toothkeeper philosophy was thoroughly presented: "the Toothkeeper" film was shown in addition to the 10-minute film "How to be a Toothkeeper" and instructions given for the use of these films in the classrooms. Local dentists and dental hygienists participated as consultants and instructors of small groups, and demonstrated recommended brushing, flossing, and disclosing methods to the teachers in the Toothkeeper group.

The in-service training session for the "Traditional" group, conducted by the reporters (RCG, DRM, BGW), was held for the same length of time as the Toothkeeper workshop and focused on discussions of the contents and possible uses of the materials in the teaching kits supplied by the Michigan Dental Association. Suggestions were made to teachers concerning the content of their largely didactic presentations to the classes. The classroom sessions were to be for 30 minutes daily for the first three weeks, gradually reduced to 15 minute sessions three times per week for the remaining weeks to be comparable with the time devoted by the Toothkeeper program. Supplies of toothbrushes, dental floss, and 
disclosing tablets similar to those used in the Toothkeeper activity were given to these students for their use at home.

\section{Examination Methods}

Baseline dental examinations were conducted of participants immediately before the study began. Under artificial light, dental mirrors and explorers were used to determine the status of oral health including scoring for dental plaque and gingivitis, according to modified methods described by Loe and Silness. 6,12 The same two calibrated examiners (RCG and DRM) surveyed all of the participating children at baseline, after the intensive 16-week oral hygiene education sessions, and immediately prior to the end of the school year, some seven months after the initial examinations. At no time did the examiners have knowledge of the study group to which a child was assigned.

\section{Findings}

Of the 476 subjects examined initially, results for the 409 children who were present for all three examinations are presented in Tables 1 and 2 . Changes observed between baseline and after four months represent the 16-week intensive period of the dental health education program. Changes observed between four months and seven months represent the period following the intensive program to the end of the school year. It may be observed in Table 1 that average plaque scores were reduced by only 0.06 in the "Traditional" group and 0.28 in the Toothkeeper group during the first 16 weeks. During the next three months plaque scores were reduced only slightly, 0.08 , in the "Traditional" group, but actually rose by 0.09 for the Toothkeeper group. Thus, at the end of the school year, average plaque scores were only lower by 0.14 than initial scores for the "Traditional" group and only 0.19 for the Toothkeeper group.

As observed in Table 2, gingivitis scores were reduced to a greater extent than plaque scores. During the intensive study period, average gingivitis scores were lowered by 0.38 in the "Traditional" group and by 0.54 in the Toothkeeper group. During the last three months of the school year, these scores actually went up so that reductions for the total length of the evaluation period were only 0.25 for the "Traditional" group and only 0.35 for the Toothkeeper group, representing percent reductions of 22 percent and 27 percent respectively. Analyses of the findings according to sex and grade did not prove to be appreciably different from the combined results for the two experimental groups. Consistent with many other studies, boys tended to have poorer scores than girls and the children in upper grades had scores poorer than those in lower grades.

\section{Discussion}

Practical considerations of the disadvantages of having students in the same classroom in different experimental programs required that entire classrooms of students be randomly assigned to the same experimental program. Hence, it is not unreasonable that by chance the Toothkeeper group had both higher baseline plaque and baseline gingivitis scores than the "Traditional" group. A univariate analysis of variance was calculated to confirm that the baseline scores for the two groups were statistically significantly different. Because of these different baseline values, statistical analyses concentrated on mean changes in scores that occurred from one time to another, particularly from baseline to the end of the intensive period ( 4 months) and from baseline to the end of the school year ( 7 months). Statistically significant reductions in plaque and gingivitis scores were observed for the Toothkeeper group compared to the "Traditional" group during the intensive phase of the program. However, this advantage over the "Traditional" group was lost for the total evaluation period (baseline to 7 months.)

Though different statistically, it is questionable whether plaque scores of 1.83 and 1.99 have any meaningful difference clinically. The small reduction in plaque scores from the beginning to the end of the school year (less than 10 percent in the Toothkeeper group) indicates little promise for either program. Some hope based on the drop in mean plaque scores from 1.99 to 1.71 might be generated for the Toothkeeper program if appropriate 
disclosing tablets similar to those used in the Toothkeeper activity were given to these students for their use at home.

\section{Examination Methods}

Baseline dental examinations were conducted of participants immediately before the study began. Under artificial light, dental mirrors and explorers were used to determine the status of oral health including scoring for dental plaque and gingivitis, according to modified methods described by Loe and Silness. 6,12 The same two calibrated examiners (RCG and DRM) surveyed all of the participating children at baseline, after the intensive 16-week oral hygiene education sessions, and immediately prior to the end of the school year, some seven months after the initial examinations. At no time did the examiners have knowledge of the study group to which a child was assigned.

\section{Findings}

Of the 476 subjects examined initially, results for the 409 children who were present for all three examinations are presented in Tables 1 and 2. Changes observed between baseline and after four months represent the 16-week intensive period of the dental health education program. Changes observed between four months and seven months represent the period following the intensive program to the end of the school year. It may be observed in Table 1 that average plaque scores were reduced by only 0.06 in the "Traditional" group and 0.28 in the Toothkeeper group during the first 16 weeks. During the next three months plaque scores were reduced only slightly, 0.08 , in the "Traditional" group, but actually rose by 0.09 for the Toothkeeper group. Thus, at the end of the school year, average plaque scores were only lower by 0.14 than initial scores for the "Traditional" group and only 0.19 for the Toothkeeper group.

As observed in Table 2, gingivitis scores were reduced to a greater extent than plaque scores. During the intensive study period, average gingivitis scores were lowered by 0.38 in the "Traditional" group and by 0.54 in the Toothkeeper group. During the last three months of the school year, these scores actually went up so that reductions for the total length of the evaluation period were only 0.25 for the "Traditional" group and only 0.35 for the Toothkeeper group, representing percent reductions of 22 percent and 27 percent respectively. Analyses of the findings according to sex and grade did not prove to be appreciably different from the combined results for the two experimental groups. Consistent with many other studies, boys tended to have poorer scores than girls and the children in upper grades had scores poorer than those in lower grades.

\section{Discussion}

Practical considerations of the disadvantages of having students in the same classroom in different experimental programs required that entire classrooms of students be randomly assigned to the same experimental program. Hence, it is not unreasonable that by chance the Toothkeeper group had both higher baseline plaque and baseline gingivitis scores than the "Traditional" group. A univariate analysis of variance was calculated to confirm that the baseline scores for the two groups were statistically significantly different. Because of these different baseline values, statistical analyses concentrated on mean changes in scores that occurred from one time to another, particularly from baseline to the end of the intensive period ( 4 months) and from baseline to the end of the school year ( 7 months). Statistically significant reductions in plaque and gingivitis scores were observed for the Toothkeeper group compared to the "Traditional" group during the intensive phase of the program. However, this advantage over the "Traditional" group was lost for the total evaluation period (baseline to 7 months.)

Though different statistically, it is questionable whether plaque scores of 1.83 and 1.99 have any meaningful difference clinically. The small reduction in plaque scores from the beginning to the end of the school year (less than 10 percent in the Toothkeeper group) indicates little promise for either program. Some hope based on the drop in mean plaque scores from 1.99 to 1.71 might be generated for the Toothkeeper program if appropriate 
reinforcement methods are applied following the 16 weeks' program. A decrease in plaque scores would certainly be anticipated, because of the supervised classroom brushing and flossing. This 14 percent reduction comes far short, however, of the benefit proclaimed by a promotional Toothkeeper folder ${ }^{2}$ which states: "You can help reduce dental disease 90 percent with the Toothkeeper technique."

The much greater reduction in gingivitis scores compared to plaque scores seems somewhat perplexing. A possible explanation might be that the school made a commitment to improving the oral health of the students and employed a dental hygienist three days a week. In addition to serving as a consultant to the teachers, the dental hygienist performed a large number of dental prophylaxes for students at the school as well as conducting a busy referral program to the Mott Children's Clinic and private dentists for care. In performing the prophylaxes and in making referrals for dental treatment, no consideration was given to which group a student was assigned.

It has been observed 5,7 that following prophylaxis, the development of gingivitis lags behind the buildup of plaque on tooth surfaces. Thus, in a population in which significant numbers have received recent prophylaxes, gingivitis scores might reasonably be lower than plaque scores would tend to indicate. The 41 percent reduction in gingivitis scores observed for those in the Toothkeeper group during the intensive 16-week period of the programs perhaps offers some encouragement that continued reinforcement activities might bring further improvement. The "Traditional" group, however, experienced a 33 percent reduction in gingivitis scores during the 16-week period. The majority of prophylaxes were rendered during the intensive period of the program and not during the three month period at the end of the school year, suggesting that the prophylaxes and not the experimental programs may have accounted for some of the improvement in gingival health.

\section{Summary}

A study was made of the effectiveness of two dental health education programs in an elementary school in Flint, Michigan. Following stratification by grades, random assignments of students were made by classrooms to either the Toothkeeper group or a "Traditional" group. No control groups were employed. Separate in-service training workshops were attended by the classroom teachers according to the education program to which they had been randomly assigned. An intensive 16-week program was conducted by the classroom teachers following the guidelines of the two programs. Dental examinations which included an assessment of plaque and gingivitis scores were conducted on all participants at baseline, at the end of 16 weeks, and at the conclusion of the school year, some seven months after the initiation of the program.

Only minimal reductions in plaque scores were observed with either program and little comparative difference was found in the two programs at the end of the evaluation period. The Toothkeeper group experienced a somewhat greater reduction in plaque scores than the "Traditional" group during the intensive 16-week phase of the study, but these scores worsened from this time to the end of the school year. Gingivitis scores demonstrated more improvement than the reductions in plaque scores would indicate and may be related to the confounding factor of large numbers of children receiving dental treatment, especially prophylaxes during the course of this study. Differences in reductions in gingivitis between the two programs were not meaningful clinically.

\section{Conclusions}

The practical considerations in this study indicate certain conclusions which necessarily are limited to the population studied:

1. Clinically meaningful plaque reductions were not demonstrated by either a "Traditional" or the Toothkeeper program.

2. The mild degree of improvement in gingival health was comparable for both the "Traditional" and the Toothkeeper groups. 
3. The mild improvement in gingival health may not be related to the effect of the programs under study, but may be because of the large numbers of students who received prophylaxes and dental care.

4. Continued efforts should be made to reinforce favorable behavior, to improve dental health education programs, and to evaluate their effectiveness.

Table 1

Mean Scores of Plaque for $\mathbf{4 0 9}$ Children by Study Groups and Examination Time, Williams School, Flint, Michigan

1972-73

\begin{tabular}{lccc}
\hline $\begin{array}{l}\text { Study Group and } \\
\text { Examination Time }\end{array}$ & $\begin{array}{c}\text { Number of } \\
\text { Students }\end{array}$ & Mean Score & $\begin{array}{c}\text { Standard Error } \\
\text { of Mean }\end{array}$ \\
\hline $\begin{array}{l}\text { Toothkeeper } \\
\text { Baseline }\end{array}$ & 217 & 1.99 & 0.046 \\
4 Months & 217 & 1.71 & 0.041 \\
7 Months & 217 & 1.80 & 0.039 \\
"Traditional" & & & \\
Baseline & 192 & 1.83 & 0.044 \\
4 Months & 192 & 1.77 & 0.046 \\
7 Months & 192 & 1.69 & 0.042 \\
\hline
\end{tabular}

NOTE: Statistical Analysis: Analysis of Variance

Baseline Plaque Scores:

Toothkeeper $=1.99$ vs. "Traditional" $=1.83, \mathrm{~F}$ value $=6.34, \mathrm{p}<.05$

Mean Change of Plaque Scores between Examination Periods:

Baseline to 4 Months:

Toothkeeper $\square .28$, "Traditional" - .06, $\mathrm{p}<.01$

Baseline to 7 Months:

Toothkeeper $=.19$, "Traditional" $\square .14, \mathrm{p}>.50$ (N.S.)

\section{Sez Stanley Heifetz}

Washington (AP) reports that Americans were victims of $\$ 400$ million for gooey dentifrice, squeezed from rumpled tubes this past year, by people in search of mint-fresh breath, pearly white teeth, cavity-free checkups, or a new love of life. Dr. Heifetz states, from the National Institute of Dental Research, "If you're going to use a dentifrice, there is no reason why it should not be one which contains fluoride and is accepted by the Council on Dental Therapeutics of the American Dental Association." 
Table 2

\section{Mean Scores of Gingivitis for 409 Children by Study Groups and Examination Time, Williams School, Flint, Michigan 1972-73}

\begin{tabular}{lccc}
\hline $\begin{array}{l}\text { Study Group and } \\
\text { Examination Time }\end{array}$ & $\begin{array}{c}\text { Number of } \\
\text { Students }\end{array}$ & Mean Score & $\begin{array}{c}\text { Standard Error } \\
\text { of Mean }\end{array}$ \\
\hline $\begin{array}{l}\text { Toothkeeper } \\
\text { Baseline }\end{array}$ & 217 & 1.31 & \\
4 Months & 217 & 0.77 & 0.047 \\
7 Months & 217 & 0.96 & 0.040 \\
"Traditional" & & & \\
Baseline & 192 & 1.15 & 0.047 \\
4 Months & 192 & 0.77 & 0.041 \\
7 Months & 192 & 0.90 & 0.043 \\
\hline
\end{tabular}

NOTE: Statistical Analysis: Analysis of Variance Baseline Gingivitis Scores:

Toothkeeper $=1.31$ vs. "Traditional" $=1.15, \mathrm{~F}$ value $=5.89, \mathrm{p}<.05$

Mean Change of Gingivitis Scores between Examination Periods:

Baseline to 4 Months:

Toothkeeper $=.54$, "Traditional" $=.38, \mathrm{p} .<.05$

Baseline to 7 Months:

Toothkeeper $\mathbf{D} .35$, "Traditional" $=.25, \mathrm{p}>.15$ (N.S.)

\section{Bibliography}

1. Ash, M. M., Gitlin, B. N., and Smith, W. A. Correlation between plaque and gingivitis. J. Periodont., 35:424-9, Sept.-Oct. 1964.

2. Den-Tal-Ez Manufacturing Company, Health Education Division. Toothkeeper; the dental disease prevention program for your schools. Des Moines, the Company, n.d., 4 p.

3. Haefner, D. P. Dental health education. p. 78-95. (In Striffler, D. F., ed. The scope of dental public health; report of a training course in dental public health administration. [New York], American Public Health Association, Dental Health Section, 1964. 193 p.)

4. Heifetz, S. B., et al. Programs for the mass control of plaque; an appraisal, J. Pub. Health Dent., 33:91-5, Spring 1973.

5. Lang, N. P., Cuming, B. R., and Löe, Harald. Toothbrushing frequency as it relates to plaque development and gingival health. J. Periodont., 44:396-405, July 1973.

6. Löe, Harald, and Silness, John. Periodontal disease in pregnancy. I. Prevalence and severity. Acta Odont. Scand., 21:533-51, Nov. 1963.

7. Loe, Harald, Theilade, Else, and Jensen, S. B. Experimental gingivitis in man. J. Periodont., 36: 177-87, May-June 1965.

8. Lovdal, Arne, et al. Combined effect of subgingival scaling and controlled oral hygiene on the incidence of gingivitis. Acta Odont. Scand., 19:537-55, Nos. 3-4, 1961.

9. Masters, D. H. The classroom teacher... effective dental health educator. Am. Soc. Preven. Dent., 2:38-45, 49, July-Aug. 1972.

10. Nyswander, Dorothy B. Solving school health problems; the Astoria demonstration study. New York, Commonwealth Fund, 1942. xii +377 p. (p. 211)

11. Rayner, Jeannette F., and Cohen, Lois K. School dental health education. p. 275-307. (In Richards, N. D., and Cohen, Lois K., eds. Social sciences and dentistry; a critical bibliography. London, Federation Dentaire Internationale, c1971. 381 p.)

12. Silness, John, and Löe, Harald. Periodontal disease in pregnancy. II. Correlation between oral hygiene and periodontal condition. Acta Odont. Scand., 22:121-35, Feb. 1964.

13. Suomi, J. D. Report of committee on research; evaluating the effectiveness of preventive dental programs. J. Pub. Health Dent., 34:56-9, Winter 1974.

14. Suomi, J. D., et al. The effect of controlled oral hygiene procedures on the progression of periodontal disease in adults; results after third and final year. J. Periodont., 42:152-60, Mar. 1971. 